\title{
Twenty Years On
}

\author{
Following a meeting of its Executive Committee, the EPS celebrated its 20th anniver- \\ sary and the Italian Physical Society its 90th anniversary at a joint Seminar in Pisa on \\ the Past and Future of Physics in Europe.
}

Pisa by candlelight. As twilight descended, the electric lights were doused and in the space of a few minutes only, candles by the tens of thousand came alight, and the historic buildings of Pisa and the banks of the Arno were bathed in their warming glow, while down the Arno itself, burning candles floated on their way to the distant sea. Not expressly for the European Physical Society nor even the Italian Physical Society we must admit. Pisa has been honouring annually its Patron Saint Ranieri in this way for the past 300 years.

A dramatic setting nevertheless for the EPS 20th anniversary in this city which physicists probably most remember as the home of Galileo and the leaning tower. Equally dramatic was the storm which followed, bringing torrential rain in the hours leading up to the opening of the special seminar on the Past and Future of Physics in Europe. One could only admire the robustness of our past leaders (many of whom are no longer young) who bright and sprightly were there for the opening ceremony trousers soaked to the knees notwithstanding.

Participants were welcomed to the Scuola Normale Superiore by the present Director, L.A. Radicati, following which the current President of both EPS and the Italian Physical Society, Renato Ricci gave a brief summary of the many messages of congratulation he had received from senior physicists across Europe and the leaders of notably Italian institutions. He expressed our thanks for the support we had received from the Ministers of Education and of Scientific Research and Technology, CNR, INFN, ENEA and CERN. He recalled how central to the founding of EPS had been the role of the Scuola Normale Superiore in the person of Gilberto Bernardini and of the Italian Physical Society of which he was the President at that time. The link between the two societies has remained close and Ricci was proud to point out that he was the third Italian to have been elected to the presidency.

Edoardo Amaldi after recalling some of the famous names in physics of men who had been active in the foundation of EPS but are no longer with us, for example - P.M.S. Blackett, Wolfgang
Gentner, John Adams, Bernard Gregory - traced the history of the Italian Physical Society. Although formally founded in 1897, its beginnings go back to 1839 when the first collective activity began — again in Pisa - followed in 1843 by a publication which later split into medical and natural sciences leading in turn eventually to the creation of // Nuovo Cimento exclusively for physics.

Bernardini himself, a vibrant example of the Italian concept of physics - a transcultural activity at the very heart of civilized concepts - summed up this approach by quoting Richard Feynman, speaking at the fourth centenary celebrations of Galileo's birth... 'we should teach wonders and the knowledge needed to appreciate these wonders'. In his own inimitable style, in which passion and firmness are made subsidiary to gentleness and courtesy, Bernardini regretted the modern tendency to see science as irrelevant to society except in its applications to technology.

A glimpse by your editor of the views of the late Erik Rudberg, founder member and EPS President from 1970-72, who, in an interview, had talked of EPS as a powerful instrument for bringing east and west together, and then on to the physics. First though a small alteration to the programme to accommodate another phenomenon of Italian physics, Antonino Zichichi (EPS President from 1978-80), whose travel plans had been disturbed by the bad weather and who could in consequence make only a fleeting appearance and then by courtesy of the Italian Air Force. Where else in Europe could one find such importance accorded to a scientific meeting and where else, as we learned from R.L. Mössbauer in his opening talk on neutrinos, would a country be willing to postpone the opening of a major autoroute section through a mountain, while a new physics laboratory was hewed out and equipped alongside? Yet this is just what has been happening in the Gran Sasso.

Mössbauer made us realise how little we know at present about neutrinos even how many there were, why there appeared to be several flavours, whether their conservation was exact, whether they were Dirac or Majorana particles quite apart from their mass. We could observe, however, that they were a major source of international collaboration, notably in the building of $\mathrm{Ga}$ detectors to study the ${ }^{71} \mathrm{Ga}+v \rightarrow{ }^{71} \mathrm{Ge}+\mathrm{e}^{-}, \mathrm{a}$ reaction with a threshold of $0.23 \mathrm{MeV}$.

From H.O.G. Alfvén, a controversal approach is always to be expected and we were not disappointed. After paying homage to the instrument builders who, he maintained, were the mainspring of scientific advance, he talked of the plasma Universe and the need to examine it experimentally rather than through the medium of differential equations. The fashion in the last decades had been to want to describe plasma in terms of fields when what counted, and were there to be measured, was currents. If we could reverse the trend then we could begin thinking in terms of plasma cosmology instead of always Big Bang cosmology.

L. Woltjer also made us aware of the dependence of progress in physics on the instrument makers as he described the joint programmes aimed to extend the conquest of the whole EM observing range and the plans for the next generation of optical telescopes, notably ESO's Very Large Telescope (Europhys. News, $19,7 / 8,99$ ).

Zichichi too chose to concentrate on machines and detectors outlining the hugely ambitious project, the Eloisatron which he sees as only another step along the road to the Planck mass. The Eloisatron is a $2 \times 100 \mathrm{TeV}$ collider that would be built round a ring $100 \mathrm{~km}$ across. It would require a world-wide collaboration and would mark the end of specialised particle experiments. Collisions would be recorded in toto and specialised analyses would follow. Seven potential sites had been identified. Zichichi believes that now we are in a position to imagine discoveries of fabulous interest, whereas in the past as each new range of energy opened up we were feeling our way in the dark.

And so the programme of talks developed with new ideas and new challenges falling over each other. A. Schlüter surveyed the efforts being made to make thermo-nuclear fusion a practical reality. $\mathrm{J}$. Muller brought us up to date on the new high temperature superconductors, reminding us that although they have 
$\rightarrow$ Six of the ten EPS Presidents. From left to right:

R.A. Ricci, Legnaro, 1988-

H.B.G. Casimir, Eindhoven, 1972-76

G.H. Stafford, Oxford, 1984-86

G. Bernardini, Pisa, 1968-70

A.R. Mackintosh, Copenhagen, 1980-82

W. Buckel, Karlsruhe, 1986-88
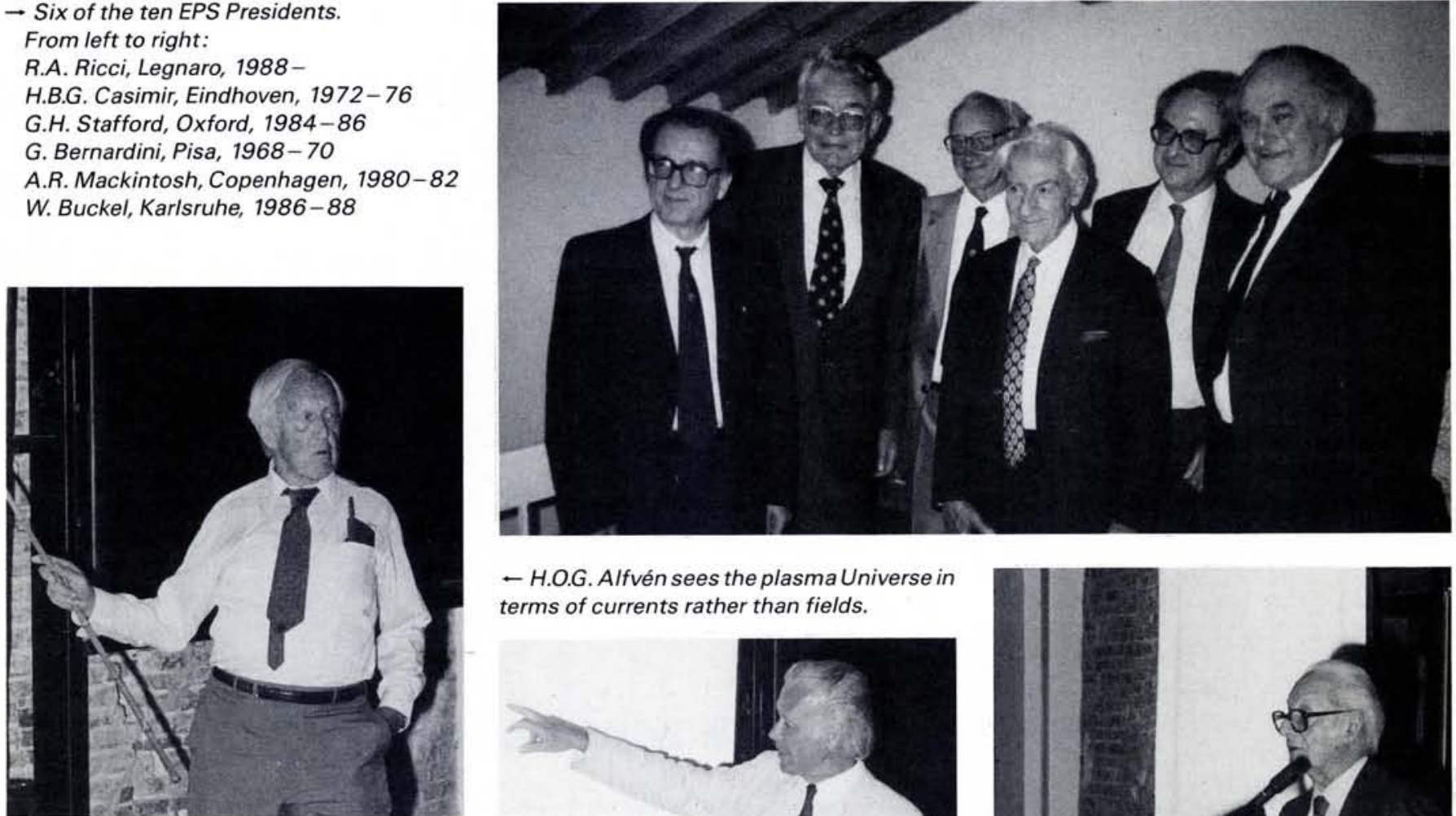

- H.O.G. Alfvén sees the plasma Universe in terms of currents rather than fields.

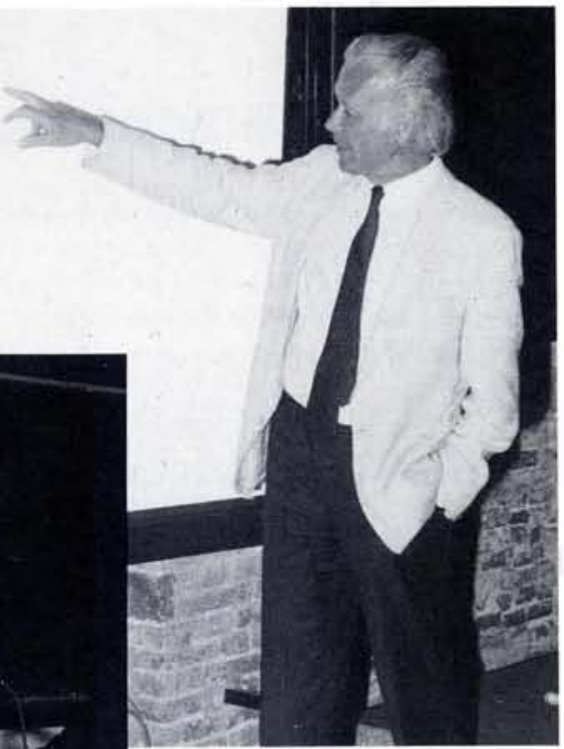

I L. Woltjer describes the ingenuity needed to build the European Very Large Telescope.

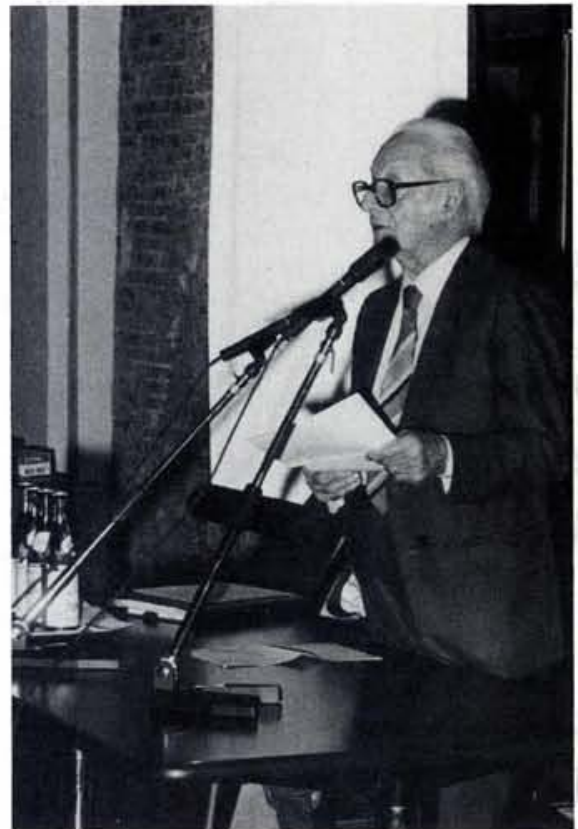

$\dagger$ E. Amaldi recalls the history of the Italian Physical Society interwoven with that of II Nuovo Cimento.

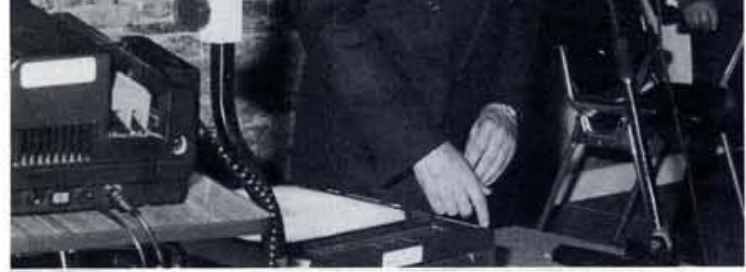

I R.L. Mössbauer outlines the massive experiments designed to elucidate the mysteries of the neutrinos.
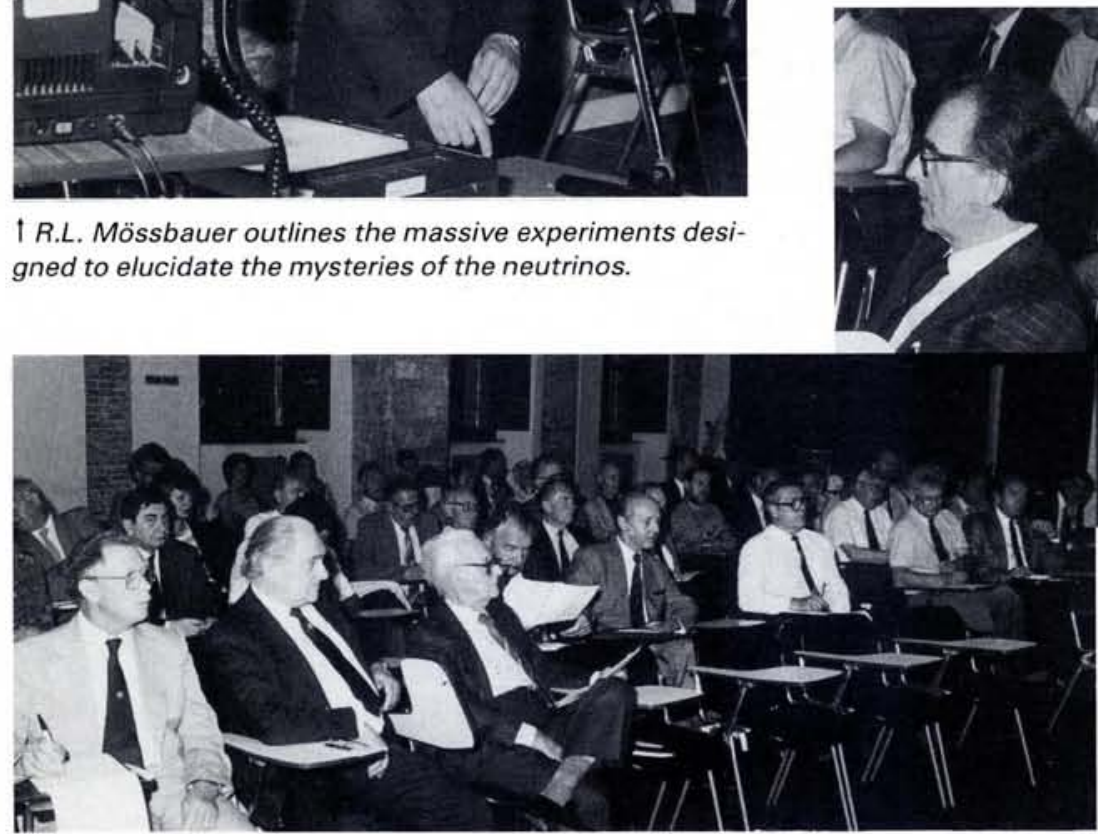

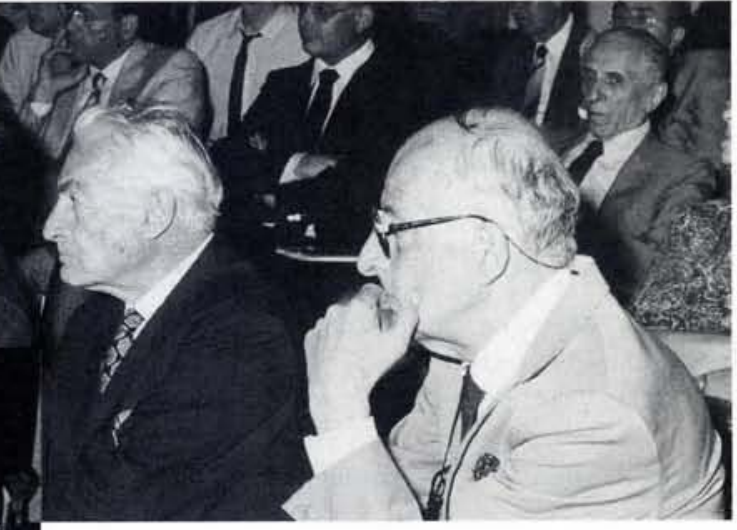

I R.A. Ricci, G. Bernardini and B. Pontecorvo enthralled by A. Zichichi's visions of an accelerator $300 \mathrm{~km}$ round.

- Some of the participants who braved the torrential rain to attend the opening session. 
been less in the headlines over the past six months, progress towards characterising these new materials and inventing others was still going on at a rapid rate and any survey was likely to be out of date in a few months' time.

Promise of new things to come but not yet with us from the heavy ion experiments at CERN with oxygen and sulphur ions striking a tungsten target were evoked by $\mathrm{H}$. Specht, while $\mathrm{F}$. Willeumier took us through the evolution from the first synchrotron radiation experiments in 1963, when simple absorption measurements in noble gases were the latest thing, to the complexity of today's two electron-three photon transition studies. On the horizon was the $6 \mathrm{GeV}$ ESRF machine being built in
Grenoble (for which site clearance had now been completed) which would give us an increase in brightness of orders of magnitude.

G. Salvini intrigued with his inversion of the usual connotation given to 'pure' and 'applied' physics by pointing out that high energy physics in its use of solid state detectors was the applied end of pure solid state research. Indeed physics was interactive, and techniques - both practical and theoretical developed in one field could find outlets in other fields. Yu Gulyaev expanded on this theme by describing the growing importance of the techniques based on physics used for the dynamic mapping of the physical fields of biological objects amongst which SQUIDS for mapping magnetic fields was a topical example.

And joining both physics and biology, $\mathrm{H}$. Haken reviewed the advances that had been made in understanding the principles behind self-organisation irrespective of the nature of the organism in question. It seemed that a few degrees of freedom were behind the 'instinct' that seemed to control the apparently widely disparate ordering in these and other fields of experience.

Altogether a most fitting and rewarding two days, punctuated by a banquet held high in the adjacent hills and featuring local food and wine, a little music, a few speeches and a great deal of bonhomie.

E.N. Shaw

\title{
EPS Under the Microscope
}

\begin{abstract}
At its meeting in Pisa in June, the Executive Committee had before it a paper drawn up by Dr. Derek Stacey, one of the nine delegates to Council of the Individual Ordinary Members. He had taken the initiative in Dresden to bring together the IOM delegates present to talk about their role in the EPS and that of the IOMs. Below is a condensed version of the original paper that emerged from that discussion which took its themes from the publicity leaflet of the EPS promoting the Society. It is followed by a summary of the first reactions of the members of the Executive Committee drawn up by the acting Secretary Dr. Walter Merz.
\end{abstract}

Why don't more physicists join the EPS? What do members perceive to be the value of membership?

These are crucial questions for the EPS, since to remain viable it must have a thriving membership which plays an active role in the Society's affairs. The questions were discussed - not, of course, for the first time - at the EPS Council Meeting at Dresden in March following which the delegates of the Individual Ordinary Members present prepared a discussion document examining the relationship between the EPS and its IOM's and suggesting ways in which this relationship might be improved.

Preparing it, however, presented a major problem - which was itself at the heart of the issues we were trying to address. We were working in the dark; we had simply to guess at the attitudes of IOM's, there being no ready means of consultation. Although we went ahead and produced the document, both the Executive Committee and the delegates consider that the best way forward is to have the issues widely debated.

\section{The European Dream}

There can be little doubt that most of us joined the EPS to further the cause of the European Dream - the vision of a united Europe, with physicists playing their part in a Society which transcends national barriers. The outgoing President at Dresden, Professor Buckel, expressed the view that the question for IOM's is not "What do we get out of the EPS?" but "How can we advance the cause of the European Dream?" Let us then examine how far the EPS (in its present form) gives us this opportunity. We take the various features of being an IOM, as described in EPS literature, and discuss them mainly in this light. However, we are also interested in their general attractiveness to IOM's, since they are the specific advantages put forward as reasons for joining and remaining in the Society.

"IOM's are entitled to join any Division, Section or Inter-Divisional Group without restriction"

When an IOM does so, what benefit does he receive, and what communication does he actually have with that body? A few IOM's become members of Boards, and get drawn into the Society's activities that way. What news or scientific communications do the others get as a result of joining? Is the level of communication between Boards and their affiliated IOM's adequate, or does it consist mainly of the circulation of ballot papers? One cannot participate in something if one does not know what is going on. It would be particularly useful to have feedback from IOM's on this point.

"IOM's receive the monthly bulletin Europhysics News free of charge"

The journal is clearly a plus, but despite its undoubted virtues - it certainly plays the European Dream theme, and there are good scientific articles - it seems unlikely that the IOM feels very involved with the EPS through this channel. It is impersonal; the IOM is not invited to contribute comments or enter into discussion, and the various Boards seem to make little use of the journal to pass on news to their members.

"IOM's... enjoy reduced rates of subscription to journals"

Another plus; but it is hard to imagine it is a major selling point, at least to younger physicists. Few who have to manage on academic salaries would take out personal subscriptions to a general publication like the European Journal of Physics, excellent though it is. 